\title{
Incidence of breast and gynaecological cancers by ethnic group in England, 2001-2007: a descriptive study
}

Megan H Shirley ${ }^{1}$, Isobel Barnes ${ }^{1}$, Shameq Sayeed ${ }^{1}$, Alexander Finlayson ${ }^{1}$ and Raghib $\mathrm{Ali}^{1,2^{*}}$

\begin{abstract}
Background: Although international comparisons reveal large geographical differences in the incidence of breast and gynaecological cancers, incidence data for ethnic groups in England remains scarce.

Methods: We compared the incidence of breast, ovarian, cervical and endometrial cancer in British Indians, Pakistanis, Bangladeshis, Black Africans, Black Caribbeans, Chinese and Whites between 2001 and 2007. We identified 357,476 cancer registrations from which incidence rates were calculated using mid-year population estimates from 2001 to 2007. Ethnicity was obtained through linkage to the Hospital Episodes Statistics database. Incidence rate ratios were calculated, comparing the 6 non-White ethnic groups to Whites, and were adjusted for age and income.

Results: We found evidence of differences in the incidence of all 4 cancers by ethnic group $(p<0.001)$. Relative to Whites, South Asians had much lower rates of breast, ovarian and cervical cancer (IRRs of 0.68, 0.66 and 0.33 respectively), Blacks had lower rates of breast, ovarian and cervical cancer but higher rates of endometrial cancer (IRRs of $0.85,0.62,0.72$ and 1.16 respectively), and Chinese had lower rates of breast and cervical cancer (IRRs of 0.72 and 0.68 respectively). There were also substantial intra-ethnic differences, particularly among South Asians, with Bangladeshis experiencing the lowest rates of all 4 cancers.
\end{abstract}

Conclusions: Our study provides evidence that the risk of breast and gynaecological cancers varies by ethnic group and that those groups typically grouped together are not homogenous with regards to their cancer risk. Furthermore, several of our findings cannot be readily explained by known risk factors and therefore warrant further investigation.

Keywords: Breast cancer, Ovarian cancer, Endometrial cancer, Cervical cancer, Epidemiology, Ethnic groups, Incidence

\section{Background}

Together, breast and gynaecological cancers make up a third of all female cancer registrations in England [1]. Worldwide, they cause 0.7 million deaths each year, with breast and cervical cancer among the top 3 biggest causes of cancer-related death among females [2].

There is considerable geographic variation in the incidence of these cancers; whilst breast, ovarian and endometrial cancers are roughly twice as common in developed

\footnotetext{
* Correspondence: raghib.ali@ndm.ox.ac.uk

${ }^{1}$ Cancer Epidemiology Unit, University of Oxford, Richard Doll Building, Oxford OX3 7LF, UK

${ }^{2} 17666$ Al Ain, United Arab Emirates
}

compared to developing countries, the reverse is true of cervical cancer for which $85 \%$ of new cases occur in less developed regions [2].

Studying migrant populations may provide insights into the risk factors underlying these differences and inform the planning of healthcare provision among minority ethnic groups [3]. In addition, as similar diagnostic, reporting and registration procedures are used, such studies overcome many of the limitations of international comparisons [3].

Non-White ethnic groups comprise around $14.1 \%$ of the English and Welsh population, the largest group being South Asians (Indians, Pakistanis and Bangladeshis),

\section{Biomed Central}


followed by Blacks (Black Africans and Black Caribbeans) and Chinese [4]. Results from previous studies suggest that South Asians experience much lower rates of breast cancer and slightly lower or similar rates of ovarian, cervical and endometrial cancer compared to Whites [5-8]. Studies among Blacks reveal lower rates of breast and ovarian cancer and slightly higher rates of cervical and endometrial cancer $[5,9,10]$.

However, data on the incidence of these cancers by ethnic group remains very limited, particularly for the gynaecological cancers. Furthermore, the terms South Asian and Black encompass a number of more specific ethnicities, each with their own unique lifestyle, culture and characteristics. Until recently, it has been difficult to obtain reliable ethnicity information for these individual ethnic groups [11], and most studies have tended to group them together under broader categories instead. However, it is now possible to link cancer registrations to self-assigned ethnicity data recorded on the Hospital Episodes Statistics database (HES) (http://www.hscic. gov.uk/hes), providing more reliable, higher resolution ethnicity information [11].

This study sought to explore differences in the incidence of breast and gynaecological cancers between Indians, Pakistanis, Bangladeshis, Black Africans, Black Caribbeans, Chinese and Whites in England between 2001 and 2007 using self-assigned ethnicity.

\section{Methods}

The methods used in this study were broadly the same as those described in our previous studies $[12,13]$.

\section{Data collection}

The National Cancer Intelligence Network (NCIN) provided data for all cancer registrations from January 2001 to December 2007 for residents in England. For each registration, the following information was given: cancer site coded to the International Classifications of Diseases, 10th Revision (ICD-10) [14]; deprivation assessed from the income domain of the Index of Multiple Deprivation 2007 (IMD 2007) [15]; age at diagnosis of cancer; and ethnicity. We used mid-year population estimates produced by the Office for National Statistics (ONS) from 2001-2007, stratified by age and ethnicity. Population data stratified by national quintiles of the income domain were provided by the ONS based on the 2001 census and the same distributions applied to population data by age and ethnicity for the 2001-2007 midyear population estimates.

\section{Classification of ethnicity}

The NCIN obtained the self-assigned ethnicity for each cancer registration by record linkage to the HES database. If a cancer registration could not be linked, or if ethnicity was missing on the HES database, ethnicity was assigned using the cancer registry data. Prior to April 2001, ethnicity was classified by HES and the cancer registries according to the codes used in the 1991 census. After April 2001, the codes were amended to those used in the 2001 census, although 1991 ethnicity codes were accepted until 2003. For the analyses presented in this paper, ethnicity was classified as White ('White' from the 1991 Census and 'White British' from the 2001 Census), Indian, Pakistani, Bangladeshi (with the three groups combined to form the category 'South Asian'), Black African, Black Caribbean (again both combined to form the category 'Black') and Chinese. (Sri Lankans are not recorded as a separate ethnic group in the census or HES data and so are not included in our analysis).

\section{Classification of malignancies}

We included cancers of the breast (ICD-10 code: C50), ovary (C56-57), cervix (C53) and endometrium (C54).

\section{Statistical analyses}

We estimated age standardised rates (ASRs) of each cancer per 100,000 person-years for all ethnic groups using direct standardisation to the 1960 Segi world population [16], with age at diagnosis of cancer being classified into 6 categories: <40, 40-49, 50-59, 60-69, $70-79$, and $\geq 80$ years. We used Poisson regression to estimate incidence rate ratios (RRs) comparing each ethnic group, and the two combined categories of South Asian and Black, to Whites adjusting for age and income.

When comparing South Asians and Blacks to Whites, we present results as IRRs and 99\% confidence intervals (CIs). When comparing the individual ethnic groups, results are presented as IRRs and 99\% floating confidence intervals (FCIs). FCIs were calculated using the method of floating absolute risks [17] and enable valid comparisons between any two ethnic groups, even if neither one is the baseline. We calculated 99\% CIs because of multiple tests performed across ethnic groups.

We performed a pre-specified subgroup analysis by age for breast cancer, with cases divided into those aged under 50 and those aged 50 or above. We decided not to analyse the gynaecological cancers by age as case numbers were too low.

Tests of heterogeneity of IRRs between ethnicities, either overall or restricted to South Asians or Blacks, were performed using likelihood $X^{2}$ ratio tests. The test of heterogeneity of IRRs between the younger and older age group for breast cancer was performed for South Asians, Blacks and Chinese using a $X^{2}$ contrast test. 


\section{Sensitivity analysis}

Because ethnicity information was not complete for all registered cancers, we used multiple imputations to assess the effect the missing values of ethnicity had on our results. We generated 40 datasets with imputed values of ethnicity using a multinomial logistic regression model where the predictor variables were age, deprivation (income) and site of cancer. We performed our primary analysis examining the effect of ethnicity on cancer for each dataset. The resulting IRRs were combined using Rubin's combination rules [18].

We performed all analyses using Stata V.12 and R statistical software packages.

\section{Graphical presentation of results}

Where results are presented in the form of plots, IRRs for each ethnic group are represented as squares and their corresponding 99\% FCIs as straight lines. For the combined South Asian and Black groups, IRRs are shown as open diamonds, whose horizontal extent indicates the $99 \%$ CI. Dashed vertical lines act as a reference, representing the IRRs for South Asians and Blacks.

\section{Comparison to rates in countries of origin}

We also compared the ASRs for each ethnic group in England to rates from their country or region of origin using data from the Globocan database [2], which is also standardised to the Segi world population [16].

This study was approved by the Oxford Research Ethics Committee.

\section{Results}

Table 1 shows the demographic characteristics of each ethnic group. Bangladeshis, Pakistanis and Black Africans have the youngest populations, with only around $10 \%$ of their population being over 50 years old. These groups also have the highest levels of deprivation (as measured by the income domain of the IMD 2007), with Whites and Chinese being the least deprived groups. Around half of South Asians and Black Caribbeans were born in the UK compared to only around 30\% of Blacks Africans and Chinese.

Table 2 shows the number of cancer registrations and missing ethnicity values for each cancer by individual ethnic group. Overall, there were 357,476 cases, of which $72,985(20.4 \%)$ had no recorded ethnicity data. When analysed by age, the percentage of breast cancer cases with missing ethnicity for under and over 50s was 17.5\% and $21.8 \%$ respectively (data not shown).

Figures 1 and 2 show the age-standardised incidence rates and rate ratios (adjusted by age and income) for each ethnic group compared to Whites for breast and gynaecological cancers respectively. For all 4 cancers, there was significant heterogeneity between the individual ethnic groups (all $\mathrm{p}<0.001$ ).

For breast cancer (Figure 1), all 6 non-White ethnic groups experienced lower incidence rates compared to Whites. Incidence was lowest among South Asians, at around $70 \%$ that of Whites. However, there was considerable heterogeneity within the group; whilst Indians and Pakistanis experienced similar rates, rates among Bangladeshis were considerably lower (IRRs of 50.7, 51.8 and 28.1 respectively; $\mathrm{p}<0.001$ ), at around $40 \%$ that of Whites. Rates among Blacks were around 15\% lower than those of Whites, with little difference between Black Africans and Black Caribbeans. Chinese experienced similar rates to South Asians, with incidence rates around 30\% lower than those of Whites.

Table 1 Comparison of demographic characteristics by ethnic group in England in 2001 using data from the 2001 census

\begin{tabular}{|c|c|c|c|c|c|c|c|c|c|c|c|c|c|c|}
\hline \multirow[t]{2}{*}{ Ethnic group } & \multicolumn{2}{|c|}{ White } & \multicolumn{2}{|c|}{ Indian } & \multicolumn{2}{|c|}{ Pakistani } & \multicolumn{2}{|c|}{ Bangladeshi } & \multicolumn{2}{|c|}{ Black African } & \multicolumn{2}{|c|}{ Black Caribbean } & \multicolumn{2}{|c|}{ Chinese } \\
\hline & $\mathbf{N}$ & $(\%)$ & $\mathrm{N}$ & $(\%)$ & $\mathbf{N}$ & $(\%)$ & $\mathbf{N}$ & $(\%)$ & $\mathrm{N}$ & $(\%)$ & $\mathbf{N}$ & (\%) & $\mathbf{N}$ & (\%) \\
\hline \multicolumn{15}{|l|}{ Census data for 2001} \\
\hline Total population & 21918492 & 100.0 & 517342 & 100.0 & 348496 & 100.0 & 136422 & 100.0 & 246835 & 100.0 & 301365 & 100.0 & 114768 & 100.0 \\
\hline \multicolumn{15}{|l|}{ Age } \\
\hline$<50$ & 13747228 & 62.7 & 416091 & 80.4 & 309865 & 88.9 & 123940 & 90.9 & 224906 & 91.1 & 230232 & 76.4 & 95353 & 83.1 \\
\hline $50+$ & 8171264 & 37.3 & 101251 & 19.6 & 38631 & 11.1 & 12482 & 9.2 & 21929 & 8.9 & 71133 & 23.6 & 19415 & 16.9 \\
\hline \multicolumn{15}{|l|}{ Deprivation } \\
\hline Low income & 3813688 & 17.4 & 175717 & 34.0 & 226581 & 65.0 & 99654 & 73.0 & 145962 & 59.1 & 160101 & 53.1 & 25354 & 22.1 \\
\hline Middle income & 13505394 & 61.6 & 283447 & 54.8 & 108151 & 31.0 & 33519 & 24.6 & 90493 & 36.7 & 129666 & 43.0 & 64565 & 56.3 \\
\hline High income & 4599410 & 21.0 & 58178 & 11.2 & 13764 & 4.0 & 3249 & 2.4 & 10380 & 4.2 & 11598 & 3.8 & 24849 & 21.7 \\
\hline \multicolumn{15}{|l|}{ Country of birth } \\
\hline UK & 21469693 & 98.0 & 232005 & 44.8 & 192021 & 55.1 & 63750 & 46.7 & 81451 & 33.0 & 172756 & 57.3 & 30185 & 26.3 \\
\hline Other & 448799 & 2.0 & 285337 & 55.2 & 156475 & 44.9 & 72670 & 53.3 & 165382 & 67.0 & 128612 & 42.7 & 84582 & 73.7 \\
\hline
\end{tabular}


Table 2 Distribution of registered cancers from 2001-7 in England by ethnic group, including missing ethnicity values (percentages in brackets)

\begin{tabular}{|c|c|c|c|c|c|c|c|c|c|c|c|c|c|c|c|c|c|c|c|}
\hline \multirow[b]{2}{*}{ Breast cancer } & \multicolumn{2}{|c|}{ White } & \multicolumn{2}{|c|}{ Indian } & \multicolumn{2}{|c|}{ Pakistani } & \multicolumn{2}{|c|}{ Bangladeshi } & \multicolumn{2}{|c|}{$\begin{array}{c}\text { Black } \\
\text { African }\end{array}$} & \multicolumn{2}{|c|}{$\begin{array}{c}\text { Black } \\
\text { Caribbean }\end{array}$} & \multicolumn{2}{|c|}{ Chinese } & \multicolumn{2}{|c|}{$\begin{array}{l}\text { All other } \\
\text { ethnic } \\
\text { groups }\end{array}$} & \multicolumn{2}{|c|}{$\begin{array}{c}\text { No } \\
\text { ethnicity } \\
\text { recorded }\end{array}$} & \multirow{2}{*}{$\begin{array}{c}\text { Total } \\
258917\end{array}$} \\
\hline & 182478 & $(70.5)$ & 2194 & $(0.8)$ & 1005 & $(0.4)$ & 194 & $(0.1)$ & 936 & $(0.4)$ & 1674 & $(0.6)$ & 540 & $(0.2)$ & 15565 & $(6.0)$ & 54331 & $(21.0)$ & \\
\hline Ovarian cancer & 30579 & $(72.5)$ & 288 & $(0.7)$ & 185 & $(0.4)$ & 42 & $(0.1)$ & 117 & $(0.3)$ & 181 & $(0.4)$ & 101 & $(0.2)$ & 2404 & $(5.7)$ & 8289 & (19.6) & 42186 \\
\hline Cervical cancer & 12113 & $(69.7)$ & 129 & $(0.7)$ & 66 & $(0.4)$ & 22 & $(0.1)$ & 150 & $(0.9)$ & 137 & $(0.8)$ & 54 & $(0.3)$ & 1367 & (7.9) & 3351 & (19.3) & 17389 \\
\hline $\begin{array}{l}\text { Endometrial } \\
\text { cancer }\end{array}$ & 28449 & $(73.0)$ & 398 & $(1.0)$ & 161 & $(0.4)$ & 27 & $(0.1)$ & 131 & $(0.3)$ & 338 & $(0.9)$ & 111 & $(0.3)$ & 2355 & $(6.0)$ & 7014 & $(18.0)$ & 38984 \\
\hline All four cancers & 253619 & (70.9) & 3009 & $(0.8)$ & 1417 & $(0.4)$ & 285 & $(0.1)$ & 1334 & $(0.4)$ & 2330 & $(0.7)$ & 806 & $(0.2)$ & 21691 & $(6.1)$ & 72985 & $(20.4)$ & 357476 \\
\hline
\end{tabular}

Sub-group analysis of breast cancer cases revealed strong evidence of heterogeneity by age in both South Asians and Blacks. Among South Asians, the IRR was lower among under 50s compared to over 50 s (IRRs of 0.63 and 0.71 respectively; $\mathrm{p}=0.002$ ). Blacks, on the other hand, showed the reverse pattern, with under 50s showing no difference to Whites and over 50s experiencing rates around $20 \%$ lower than Whites (IRRs of 0.96 and 0.78 respectively; $\mathrm{p}<$ 0.001 ). There was no evidence of heterogeneity by age for Chinese.

For ovarian cancer (Figure 2), incidence was lowest among South Asians and Blacks, at around 60-65\% that of Whites. However, within the South Asian group there was strong evidence of heterogeneity, with Indians and Bangladeshis experiencing lower rates compared to Pakistanis (IRRs of $0.59,0.56$ and 0.84 respectively; $\mathrm{p}<0.001)$. Similarly, there was also evidence of heterogeneity within the Black group, with Black Africans experiencing slightly higher rates than Black Caribbeans (IRRs of 0.74 and 0.56 respectively; $\mathrm{p}=0.01$ ). No difference was observed between Chinese and Whites.

For cervical cancer (Figure 2), incidence was lowest among South Asians, with rates approximately two thirds lower than those of Whites. There was little evidence of heterogeneity within this group. Rates among Blacks and Chinese were higher, at around 70\% those of Whites. Again, there was limited evidence of heterogeneity within the Black group.

For endometrial cancer (Figure 2), there was little difference in incidence between South Asians and Whites. However, there was strong evidence of heterogeneity within the group, with Bangladeshis experiencing around half the rates of Indians and Pakistanis (IRRs of $0.48,0.94$ and 0.94 respectively; $\mathrm{p}<0.001$ ). Rates among Blacks were slightly higher than those of Whites, with no difference observed between Black Africans and Black Caribbeans. Chinese had a slightly higher IRR than Blacks but the confidence intervals were wide.

\section{Sensitivity analysis}

Assigning missing ethnicity values using multiple imputation generated results very similar to those obtained in our main analysis (Additional file 1: Figure S1).

\section{Comparison to rates in country of origin}

Table 3 shows a comparison of our data with international incidence data from Globocan. For breast cancer, incidence rates from our study were higher than those of the countries of origin, with the exception of Bangladesh for which rates were very similar. For ovarian cancer, rates for all ethnicities were all slightly lower in the countries of origin, especially for China. Cervical cancer rates were higher in the country of origin for all ethnicities, particularly among South Asians. Rates of endometrial cancer were slightly lower in the country of origin for Indians, Pakistanis, Bangladeshis and Black Africans, and higher for Black Caribbeans and Chinese.

\section{Discussion}

Using self-assigned ethnicity, we compared the incidence of breast and gynaecological cancers between the 6 largest non-White ethnic groups in England and Whites. Overall, our findings indicate that there are considerable differences in the incidence of all 4 cancers by ethnicity; incidence rates for breast, ovarian and cervical cancer were highest among Whites, whereas the incidence of endometrial cancer was highest among Blacks. Furthermore, we found strong evidence of heterogeneity within the South Asian group, with Bangladeshis having the lowest rates of all 4 cancers.

Our finding that breast cancer incidence was lower in non-White ethnic groups compared to Whites is broadly consistent with previous studies from the UK [5,7-9] The particularly low incidence of breast cancer among South Asians, which has been reported elsewhere [5,7], can be largely explained by known risk factors. On average, South Asians in England have more children, are more likely to breastfeed, less likely to use HRT, much more likely to be a non-drinker, and have a lower average height than their White counterparts [19-22]. 


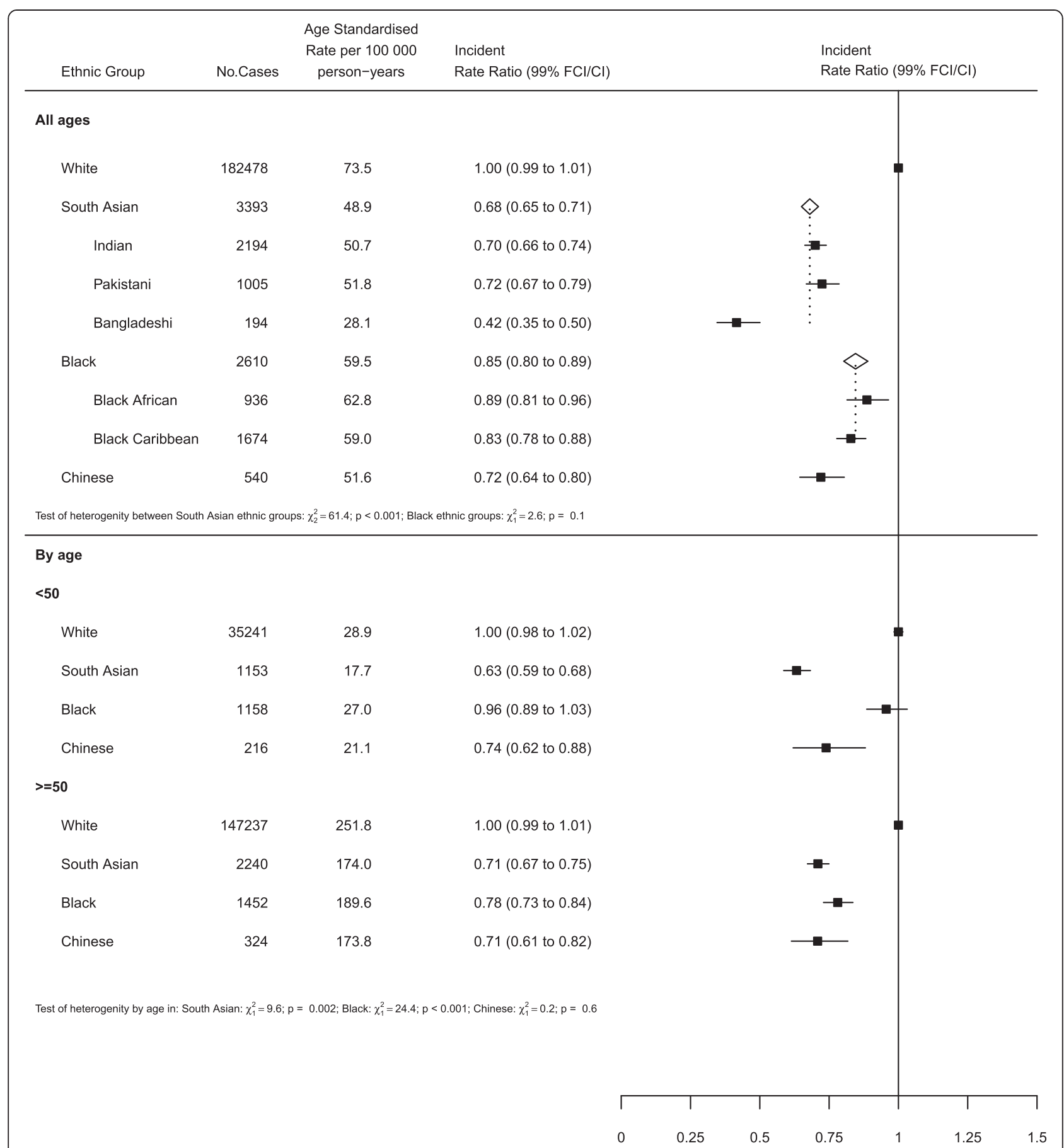

Figure 1 Age-standardised incidence rates and rate ratios (adjusted by age and income) for breast cancer by ethnic group. Subgroups show rates and rate ratios subdivided by age. $\mathrm{FCl}-99 \%$ floating confidence interval; $\mathrm{Cl}-99 \%$ confidence interval.

Indeed, a recent prospective cohort study of women aged over 50 found that, once incidence rates were adjusted for known risk factors, rates among South Asians were similar to those of Whites [19].

Ethnic differences were also observed within the South Asian group, with Bangladeshis having much lower rates than both Pakistanis and Indians, even after adjustment for socioeconomic status. This finding is consistent with other research $[7,23]$ and may be related to the higher parity, greater likelihood of breastfeeding or younger average age at first birth of Bangladeshis compared to the other South Asian groups [22-24]. Furthermore, in contrast to Indians and Pakistanis, who experienced much higher rates than their countries of origin, rates 


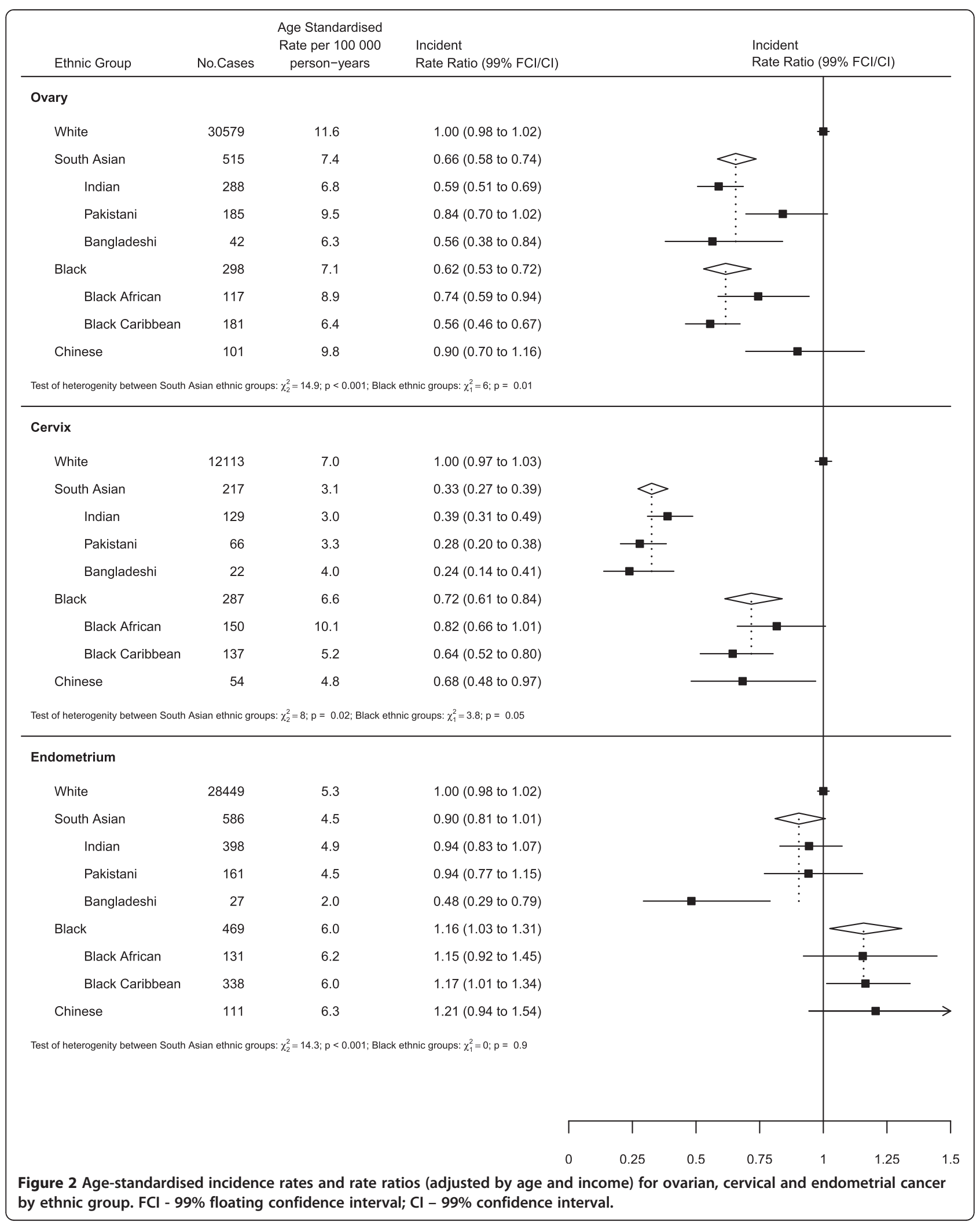


Table 3 Age-standardised incidence rates for breast and gynaecological cancers by ethnic group in England compared to rates in country of origin using estimates from Globocan

\begin{tabular}{|c|c|c|c|c|}
\hline \multirow[b]{3}{*}{ Cancer site } & \multirow[b]{3}{*}{ Ethnicity } & \multicolumn{3}{|c|}{ Females } \\
\hline & & \multicolumn{2}{|c|}{ England } & \multirow{2}{*}{$\begin{array}{c}\text { Globocan } \\
\text { ASR }\end{array}$} \\
\hline & & Cases & ASR & \\
\hline \multirow[t]{7}{*}{ Breast } & White & 182478 & 73.5 & \\
\hline & Indian & 2194 & 50.7 & 22.9 \\
\hline & Pakistani & 1005 & 51.8 & 31.5 \\
\hline & Bangladeshi & 194 & 28.1 & 27.2 \\
\hline & Black African & 936 & 62.8 & 26.3 \\
\hline & Black Caribbean & 1674 & 59.0 & 39.1 \\
\hline & Chinese & 540 & 51.6 & 21.6 \\
\hline \multirow[t]{7}{*}{ Ovary } & White & 30579 & 11.6 & \\
\hline & Indian & 288 & 6.8 & 5.7 \\
\hline & Pakistani & 185 & 9.5 & 5.8 \\
\hline & Bangladeshi & 42 & 6.3 & 4.0 \\
\hline & Black African & 117 & 8.9 & 4.0 \\
\hline & Black Caribbean & 181 & 6.4 & 4.3 \\
\hline & Chinese & 101 & 9.8 & 3.8 \\
\hline \multirow[t]{7}{*}{ Cervix } & White & 12113 & 7.0 & \\
\hline & Indian & 129 & 3.0 & 27.0 \\
\hline & Pakistani & 66 & 3.3 & 19.5 \\
\hline & Bangladeshi & 22 & 4.0 & 29.8 \\
\hline & Black African & 150 & 10.1 & 31.7 \\
\hline & Black Caribbean & 137 & 5.2 & 20.8 \\
\hline & Chinese & 54 & 4.8 & 9.6 \\
\hline \multirow[t]{7}{*}{ Endometrium } & White & 28449 & 5.3 & \\
\hline & Indian & 398 & 4.9 & 1.9 \\
\hline & Pakistani & 161 & 4.5 & 2.8 \\
\hline & Bangladeshi & 27 & 2.0 & 0.3 \\
\hline & Black African & 131 & 6.2 & 2.6 \\
\hline & Black Caribbean & 338 & 6.0 & 9.0 \\
\hline & Chinese & 111 & 6.3 & 11.1 \\
\hline
\end{tabular}

*Globocan [2] figures used are for India, Pakistan, Bangladesh, Sub-Saharan Africa, Caribbean, and China.

among Bangladeshis in our study were very similar to those reported in Bangladesh [2]. This suggests that Indian and Pakistani females may have adopted Western lifestyles and behaviours to a greater extent than Bangladeshi females. However, data on the prevalence of risk factors among Bangladeshis is very limited so further investigation would be needed to explain this disparity.

Moreover, contrary to expectations, we found that the rate ratio for South Asians compared to Whites was lower among under 50s compared to over 50s. Relative to older age groups, a much higher proportion of South Asians aged under 50 are UK born [25]. Therefore, we would expect the risk factors, and therefore incidence rates, for this group to be closer to those of Whites. Indeed, there have been significant falls in parity amongst South Asian women over the last 40 years (from 4 to 2.5) whereas the rate in White women has stayed fairly constant (less than 2) [22]. Although a previous study of breast cancer in ethnic groups found that rates for Bangladeshis and Whites were much closer in younger compared to older age groups, there was no clear effect of age among Indians or Pakistanis [7].

Like other UK studies, we also found lower incidence rates of breast cancer among Blacks compared to Whites [5,7]. Again, this difference can largely be explained by known risk factors, with Blacks having more children, being younger at first birth, more likely to breastfeed, less likely to use HRT and less likely to drink alcohol [19-21]. When analysed by age, there was a marked difference in the Black-White ratio between under 50s and over 50 s, a finding that has been reported in other studies from the UK $[5,9]$. This is despite the fact that parity amongst blacks (about 2) has not declined over the last 40 years [22]. Studies from the US have also reported a 'Black-White crossover', with higher rates of breast cancer in Blacks compared to Whites in the younger age groups and the reverse pattern in older age groups $[9,26,27]$. One study, which examined ethnic differences by molecular subtype, found that this age-related difference was largely due to high rates of triple negative breast cancer among Blacks in younger age groups and high rates of $\mathrm{HR}+/$ HER- breast cancer among Whites in older age groups [27]. However, it is unclear what risk factors would underlie these differences.

The low rates of breast cancer among Chinese in our study have been reported elsewhere in the UK $[5,7,28]$ and are consistent with international comparisons, which reveal much lower rates of breast cancer in China compared to Western countries [2,29]. Data from the Health Survey for England reveals a high prevalence of some protective factors among Chinese, including short stature, low BMI, and relatively low alcohol consumption [21]. However, Chinese women also have had the lowest parity of all ethnic groups in England since the 1980s [22]. We might also have expected rates to be lower in older Chinese women than in younger Chinese women due to the significant fall in parity over the last 40 years (from 2.2 in 1977 to 1.3 in 2006) but our results did not show any difference by age [22].

Compared to breast cancer, very few studies have investigated the incidence of gynaecological cancers by ethnicity in the UK.As far as we are aware, this is the first study to compare the incidence of gynaecological cancers by their individual ethnic groups. ((i.e. Indian, Pakistani, Bangladeshi, Black African and Black Caribbean) as opposed to the artificially combined categories of 
'Asian' and 'Black' as was done in the only previous study [5].

We observed lower rates of ovarian cancer among Blacks and South Asians compared to Whites, findings which are consistent with studies from both the UK and US [5,30,31]. These differences are likely to be attributed to the higher parity, longer duration of breastfeeding and lower HRT use among both these groups [19,20,22]. We also found evidence of intra-ethnic differences, with high incidence rates among Pakistanis and Black Africans relative to the other South Asian and Black groups. Low rates of oral contraceptive use among both these groups and low initiation of breastfeeding among Pakistanis may contribute to these higher rates $[24,32]$. However, data on the prevalence of most risk factors by individual ethnic group is scarce. In contrast, rates of ovarian cancer among Chinese were similar to Whites. This is unexpected given that their rates of breast cancer (which shares several major risk factors with ovarian cancer [33]) are so low. Rates were also higher than those reported in Hong Kong, where most Chinese in the UK originate from [29]. However, the results in Chinese are consistent with them having the lowest parity of all ethnic groups in England (as discussed above in relation to breast cancer) [22].

The incidence of cervical cancer in our study was highest in Whites and results were broadly similar to those found elsewhere in the UK [5]. The particularly low rates that we observed among South Asians have previously been documented [5,34] and may be due to the sexual behaviour of this group; although data is not available for Bangladeshis, Indians and Pakistanis tend to be older at first intercourse, have fewer sexual partners, and are less likely to be sexually active than their White counterparts [32,35]. Similarly, incidence rates among Blacks, specifically Black Caribbeans, were lower than those of Whites. Data from both England and the US has previously revealed high cervical cancer incidence rates among Blacks relative to Whites [5,36,37]. However, these results are likely to have been confounded by socioeconomic differences. Indeed, before adjusting for socioeconomic status, rates among Black Africans were actually higher than those of White in our study. Nevertheless, our finding that rates were considerably lower among Black Caribbeans is somewhat surprising, especially given that there is very little difference between the number of sexual partners, average age at first intercourse and screening uptake of Black and Whites [32,35,38].

In contrast with the other cancers studied, Blacks, specifically Black Caribbeans, had the highest rates of endometrial cancer and we found no difference in incidence between South Asians, Chinese and Whites. Indeed, previous reports from the UK have found small or no differences in incidence or mortality between South Asians and Whites [5,34,39]. Nevertheless, we found strong evidence of intra-ethnic differences in the South Asian group, with rates among Bangladeshis around 50\% lower than those of Indians, Pakistanis or Whites. Again, the shortage of data on the prevalence of risk factors limits our ability to explain these disparities. However, the lower prevalence of obesity, high parity, and higher initiation of breastfeeding among Bangladeshis may contribute to these differences $[21,23]$. The higher incidence of endometrial cancer among Blacks has previously been reported by the NCIN [5]. Racial differences in the prevalence of obesity, which is more common in Black compared to White females, may account for some of this disparity. However, in the US, where there is also a higher prevalence of obesity among Black females $[40,41]$, incidence rates among Blacks are lower than those of Whites [42,43]. Ethnic differences in the rate of hysterectomies could also contribute to these differences but, to our knowledge, there is no data available on hysterectomy rates by ethnicity in the UK.

Rates of breast, ovarian and endometrial cancer observed among the non-White ethnic groups were generally higher than their countries of origin [2]. Although this may be due to under-diagnosis or poor registration in these countries, it may also be indicative of migrants' lifestyles and reproductive behaviour becoming more similar to that of Whites. Indeed, a study of South Asians in Leicester found that rates of breast cancer among South Asians between 1990 and 1999 increased towards those reported for Whites, presumably due to younger generations adopting more western lifestyles and reproductive behaviours [44]. Cervical cancer rates, on the other hand, were lower in our study compared to data from the countries of origin [2]. This is likely to be due to the better quality and coverage of cervical screening in this country compared to less-developed countries [45], which can allow for detection and treatment of precursor lesions $[46,47]$.

To our knowledge, this is the first study to compare incidence rates of breast and gynaecological cancers between the 6 biggest non-White ethnic groups in England. Previous studies have reported breast cancer incidence among these groups but were limited to a single cancer registry $[7,9]$. Our use of self-assigned ethnicity was one of the major strengths of this study. This method of classifying ethnicity has a number of advantages over older systems, such as name analysis or the use of death certificates. Importantly, it allowed us to distinguish between similar ethnic groups, revealing patterns which would otherwise be concealed under the broad groupings of South Asian or Black. Furthermore, unlike the use of death certificates, it allows us to identify UK-born individuals, not just those born in other countries. It 
also overcomes the issue of numerator-denominator bias as the same measure of ethnicity is used for both cases (numerator) and persons at risk (denominator) [3]. Another important strength of our study is that we adjusted for socioeconomic status which is a potential confounderin studies of health and ethnicity due to the variations in deprivation between the different groups $[25,48]$.

One of the main limitations of this study is the lack of individual-level information available on risk factors. Population-level data on reproductive and lifestyle factors is available for the major ethnic groups $[19,20,22,23]$, allowing us to make broad ecological comparisons and generate hypotheses. However, there is very limited data for the individual ethnic groups and further investigation is needed in this area. Another limitation is the proportion of missing ethnicity data. Information on ethnicity was missing in approximately $20 \%$ of cases. However, this figure is much lower than previous studies conducted on earlier data $[7,9]$ and assigning ethnicity values to missing data using multiple imputation in our sensitivity analysis made no difference to our results. While the results from the imputation analyses are reassuring, they should be interpreted with caution. Multiple imputation is based on the assumption of missing at random. If this assumption does not hold, (i.e. if persons from ethnic minorities are less likely to report their ethnicity), the results may be biased [49].

\section{Conclusions}

The results of this study provide evidence of considerable differences in the incidence of breast, ovarian, cervical and endometrial cancer by ethnic group in England. Several of these differences are novel findings which cannot be readily explained by known risk factors. These include the high rates of endometrial cancer among Black Caribbeans, and the relatively high rate ratio for ovarian compared to breast cancer among Chinese. Furthermore, by analysing individual ethnic groups, we were able to identify considerable intra-ethnic differences among South Asians, in particular the unexplained low rates among Bangladeshis for all 4 cancers. Therefore, our results highlight the importance of distinguishing between different, closely related, ethnic groups and illustrate the need for further research into the aetiology underlying variations in the incidence of these cancers between different ethnic groups.

\section{Additional file}

Additional file 1: Figure S1. Age-standardised incidence rates and rate ratios (adjusted by age and income) for breast ovarian, cervical and endometrial cancer by ethnic group by ethnic group, following multiple imputation for missing ethnicity values.

\section{Competing interests}

The authors declare that they have no competing interests.

\section{Authors' contributions}

RA and IB conceived and designed the study. RA, IB and MS contributed to the analysis and interpretation of the data. MS drafted the report, which was critically revised for important intellectual content by RA and IB. All authors approved the report. RA is guarantor. All authors read and approved the final manuscript.

\section{Acknowledgements}

We thank the National Cancer Intelligence Network (NCIN) and the Office for National Statistics (ONS) for providing the data.

\section{Funding}

RA, IB and MS are employed by the Cancer Epidemiology Unit at the University of Oxford which is supported by Cancer Research UK. The sponsor of the study had no role in design and conduct of the study; collection, management, analysis, and interpretation of the data; and preparation, review, or approval of the manuscript.

Received: 17 July 2014 Accepted: 11 December 2014 Published: 18 December 2014

\section{References}

1. Office for National Statistics: Cancer Statistics Registrations, England (Series MB1), No. 41, 2010. London: Office for National Statistics; 2012. Available at: http:// www.ons.gov.uk/ons/rel/vsob1/cancer-statistics-registrations-england-seriesmb1-/no-41-2010/index.html.

2. Ferlay J, Shin H, Bray F, Forman D, Mathers C, Parkin D: GLOBOCAN 2008 V2.0, Cancer Incidence and Mortality Worldwide: IARC CancerBase No. 10. IARC: Lyon; 2010. Available at: http://globocan.iarc.fr.

3. Parkin $M$, Khlat DM: Studies of cancer in migrants: rationale and methodology. Eur J Cancer 1996, 32(5):761-771 (Oxford, England: 1990).

4. Office for National Statistics: Ethnicity and National Identity in England and Wales 2011. London: Office for National Statistics; 2012. Available at: http://www.ons.gov.uk/ons/rel/census/2011-census/key-statistics-for-localauthorities-in-england-and-wales/rpt-ethnicity.html.

5. National Cancer Intelligence Network: Cancer Incidence and Survival by Major Ethnic Group, England, 2002-2006. London: National Cancer Intelligence Network; 2009.

6. Swerdlow AJ, Marmot MG, Grulich AE, Head J: Cancer mortality in Indian and British ethnic immigrants from the Indian subcontinent to England and Wales. Br J Cancer 1995, 72(5):1312-1319.

7. Jack RH, Davies EA, Moller H: Breast cancer incidence, stage, treatment and survival in ethnic groups in South East England. Br J Cancer 2009, 100(3):545-550.

8. Downing A, West RM, Gilthorpe MS, Lawrence G, Forman D: Using routinely collected health data to investigate the association between ethnicity and breast cancer incidence and survival: what is the impact of missing data and multiple ethnicities? Ethn Health 2011, 16(3):201-212.

9. Jack RH, Davies EA, Møller H: Breast cancer and age in Black and White women in South East England. Int J Cancer 2012, 130(5):1227-1229.

10. Grulich AE, Swerdlow AJ, Head J, Marmot MG: Cancer mortality in African and Caribbean migrants to England and Wales. Br J Cancer 1992, 66(5):905-911.

11. Jack RH, Linklater KM, Hofman D, Fitzpatrick J, Møller H: Ethnicity coding in a regional cancer registry and in Hospital Episode Statistics. BMC Public Health 2006, 6:281.

12. Ali R, Barnes I, Cairns BJ, Finlayson AE, Bhala N, Mallath M, Beral V: Incidence of gastrointestinal cancers by ethnic group in England, 2001-2007. Gut 2012, 62:1692-1703.

13. Shirley MH, Sayeed S, Barnes I, Finlayson A, Ali R: Incidence of haematological malignancies by ethnic group in England, 2001-7. Br J Haematol 2013, 163(4):465-477.

14. World Health Organisation: International Statistical Classification of Diseases and Related Health Outcomes, 10th Revision. Geneva: World Health Organization; 1992.

15. Noble M, mcLennan D, Wilkinson K, Whitworth A, Barnes H, Dibben C: The English Indices of Deprivation 2007. London: Communities and Local Government; 2008 
16. Segi M: Cancer Mortality for Selected Sites in 24 Countries (1950-57). Sendai, Japan: Department of Public Health, Tohoku University of Medicine; 1960.

17. Easton DF, Peto J, Babiker AG: Floating absolute risk - an alternative to relative risk in survival and case-control analysis avoiding an arbitrary reference group. Stat Med 1991, 10:1025-1035.

18. Rubin DB: Multiple imputation for nonresponse in surveys. New York: Wiley; 1987.

19. Gathani T, Ali R, Balkwill A, Green J, Reeves G, Beral V, Moser KA: Ethnic differences in breast cancer incidence in England are due to differences in known risk factors for the disease: prospective study. Br J Cancer 2014, 110:224-229.

20. McCormack VA, Perry N, Vinnicombe SJ, Silva Idos S: Ethnic variations in mammographic density: a British multiethnic longitudinal study. Am J Epidemiol 2008, 168(4):412-421.

21. Sproston K, Mindell J: Health Survey for England. The health of minority ethnic groups. London: The Stationery Office; 2004:2006.

22. Coleman DA, Dubuc S: The fertility of ethnic minorities in the UK, 1960s-2006. Popul Stud 2010, 64(1):19-41.

23. McCormack VA, Mangtani P, Bhakta D, McMichael AJ, dos Santos SI: Heterogeneity of breast cancer risk within the South Asian female population in England: a population-based case-control study of first-generation migrants. Br J Cancer 2004, 90(1):160-166.

24. Kelly YJ, Watt RG, Nazroo JY: Racial/ethnic differences in breastfeeding initiation and continuation in the United Kingdom and comparison with findings in the United States. Pediatrics 2006, 118(5):e1428-1435.

25. Office for National Statistics: UK Census 2001. London: Office for National Statistics. Available at: http://www.ons.gov.uk/ons/guide-method/census/ census-2001/index.html.

26. Anderson WF, Rosenberg PS, Menashe I, Mitani A, Pfeiffer RM: Age-related crossover in breast cancer incidence rates between black and white ethnic groups. J Natl Cancer Inst 2008, 100(24):1804-1814.

27. Clarke CA, Keegan TH, Yang J, Press DJ, Kurian AW, Patel AH, Lacey JV Jr: Age-specific incidence of breast cancer subtypes: understanding the black-white crossover. J Nat/ Cancer Inst 2012, 104(14):1094-1101.

28. Bhopal RS, Bansal N, Steiner M, Brewster DH: Does the 'Scottish effect' apply to all ethnic groups? All-cancer, lung, colorectal, breast and prostate cancer in the Scottish Health and Ethnicity Linkage Cohort Study. BMJ Open 2012, 2(5):e001957.

29. Forman D, Bray F, Brewster DH, Gombe Mbalawa C, Kohler B, Piñeros M, Steliarova-Foucher E, Swaminathan R, Ferlay J: Cancer Incidence in Five Continents, Volume X. IARC: Lyon; 2013. Available at: http://ci5.iarc.fr.

30. Goodman MT, Howe HL, Tung KH, Hotes J, Miller BA, Coughlin SS, Chen WW: Incidence of ovarian cancer by race and ethnicity in the United States, 1992-1997. Cancer 2003, 97(10 Suppl):2676-2685.

31. Jain RV, Mills PK, Parikh-Patel A: Cancer incidence in the south Asian population of California, 1988-2000. J Carcinog 2005, 4:21.

32. Saxena S, Copas AJ, Mercer C, Johnson AM, Fenton K, Erens B, Nanchahal K, Macdowall W, Wellings $K$ : Ethnic variations in sexual activity and contraceptive use: national cross-sectional survey. Contraception 2006, 74(3):224-233.

33. Brekelmans CT: Risk factors and risk reduction of breast and ovarian cancer. Curr Opin Obstet Gynecol 2003, 15(1):63-68.

34. Barker RM, Baker MR: Incidence of cancer in Bradford Asians. J Epidemiol Community Health 1990, 44(2):125-129.

35. Fenton KA, Mercer CH, McManus S, Erens B, Wellings K, Macdowall W, Byron CL, Copas AJ, Nanchahal K, Field J, Johnson AM: Ethnic variations in sexual behaviour in Great Britain and risk of sexually transmitted infections: a probability survey. Lancet 2005, 365(9466):1246-1255.

36. Jemal A, Siegel R, Ward E, Hao Y, Xu J, Murray T, Thun MJ: Cancer statistics, 2008. CA Cancer J Clin 2008, 58(2):71-96.

37. Jemal A, Simard EP, Dorell C, Noone AM, Markowitz LE, Kohler B, Eheman C, Saraiya M, Bandi P, Saslow D, Cronin KA, Watson M, Schiffman M, Henley SJ, Schymura MJ, Anderson RN, Yankey D, Edwards BK: Annual Report to the Nation on the Status of Cancer, 1975-2009, featuring the burden and trends in human papillomavirus(HPV)-associated cancers and HPV vaccination coverage levels. J Natl Cancer Inst 2013, 105(3):175-201.

38. Sabates $R$, Feinstein $L$ : The role of education in the uptake of preventative health care: the case of cervical screening in Britain. Soc Sci Med 2006, 62(12):2998-3010.

39. Ali R, Barnes I, Kan SW, Beral V: Cancer incidence in British Indians and British whites in Leicester, 2001-2006. Br J Cancer 2010, 103(1):143-148.
40. Sherman ME, Devesa SS: Analysis of racial differences in incidence, survival, and mortality for malignant tumors of the uterine corpus. Cancer 2003, 98(1):176-186

41. Ogden CL, Carroll MD, Curtin LR, McDowell MA, Tabak CJ, Flegal KM: Prevalence of overweight and obesity in the United States, 1999-2004. JAMA 2006, 295(13):1549-1555.

42. Jamison PM, Noone AM, Ries LA, Lee NC, Edwards BK: Trends in endometrial cancer incidence by race and histology with a correction for the prevalence of hysterectomy, SEER 1992 to 2008. Cancer Epidemiol Biomarkers Prev 2013, 22(2):233-241.

43. Reeves KW, Carter GC, Rodabough RJ, Lane D, McNeeley SG, Stefanick ML, Paskett ED: Obesity in relation to endometrial cancer risk and disease characteristics in the Women's Health Initiative. Gynecol Oncol 2011 121(2):376-382.

44. Smith LK, Botha JL, Benghiat A, Steward WP: Latest trends in cancer incidence among UK South Asians in Leicester. Br J Cancer 2003, 89(1):70-73.

45. Gakidou E, Nordhagen S, Obermeyer Z: Coverage of cervical cancer screening in 57 countries: low average levels and large inequalities. PLOS Med 2008, 5(6):e132.

46. Parkin DM, Nguyen-Dinh X, Day NE: The impact of screening on the incidence of cervical cancer in England and Wales. Br J Obstet Gynaecol 1985, 92(2):150-157.

47. Peto J, Gilham C, Fletcher O, Matthews FE: The cervical cancer epidemic that screening has prevented in the UK. Lancet 2004, 364(9430):249-256.

48. Pollock AM, Vickers N: Breast, lung and colorectal cancer incidence and survival in South Thames Region, 1987-1992: the effect of social deprivation. J Public Health Med 1997, 19(3):288-294.

49. Sterne JA, White IR, Carlin JB, Spratt M, Royston P, Kenward MG, Wood AM Carpenter JR: Multiple imputation for missing data in epidemiological and clinical research: potential and pitfalls. BMJ 2009, 338:b2393.

doi:10.1186/1471-2407-14-979

Cite this article as: Shirley et al:: Incidence of breast and gynaecological cancers by ethnic group in England, 2001-2007: a descriptive study. BMC Cancer 2014 14:979.

\section{Submit your next manuscript to BioMed Central and take full advantage of:}

- Convenient online submission

- Thorough peer review

- No space constraints or color figure charges

- Immediate publication on acceptance

- Inclusion in PubMed, CAS, Scopus and Google Scholar

- Research which is freely available for redistribution 